\title{
Dealing with disaffection: the influence of work-based learning on 14-16-year-old students' attitudes to school
}

David Allan

\author{
Correspondence: david.allan@ \\ edgehill.ac.uk \\ Faculty of Education, Edge Hill \\ University, St Helens Road, Ormskirk, \\ L39 4QP, Lancashire, UK
}

\begin{abstract}
Background: Recent developments in policy concerned with raising achievement in schools have given rise to work-based learning as a mechanism for dealing with disaffection. Alongside this redress is the potential for promoting alternative pathways into further education and/or employment. This paper looks at the impact of a work-based learning programme on engagement/re-engagement for disaffected 14-16-year-olds. Drawing on data collected in a small borough in the north of England, it examines attitudes to learning in school and a vocational learning environment.

Methods: Teachers' and tutors' attitudinal scoring of disaffected students was collected in school and a work-based learning provider, and interviews were conducted with a smaller sample of the students.

Results: The retention of a strong school connection is identified as crucial in improving attitude to learning in disaffected students, while attitude and engagement is shown to be heavily interrelated. Students who solely attend a work-based learning provider are seen to further dissociate from school.

Conclusions: This study explores the relationship between engagement and attitude to learning in disaffected 14-16-year-olds. Vocational learning is seen to be highly engaging and promotes an overall improvement in general attitude to learning. In relation to school, however, there is strong evidence of reinforced negative attitudes and further disaffection when students are fully removed from this environment. Thus, the most potent recipe for dealing with disaffection in this research is shown to be a mixture of environments where a connection with school is retained.
\end{abstract}

Keywords: Disaffection; Vocational learning; Student attitudes

\section{Background}

'There is a...belief that such modes of learning [work-related] always generate more motivation than their more passive didactic counterparts' (Jamieson 1993, 55).

In recent years, educational disaffection has been a concern for schools in the UK and according to some figures it is on the rise (Jones 2013). While the transition from one institution to another can be problematic for young people, such as for students entering secondary schools in the UK (Sodha and Guglielmi 2009) or the many American high school students who arrive 'with low levels of efficacy and self-worth' (Kelly and Price

(c) 2014 Allan; licensee Springer. This is an Open Access article distributed under the terms of the Creative Commons Attribution License (http://creativecommons.org/licenses/by/4.0), which permits unrestricted use, distribution, and reproduction in any medium, provided the original work is properly credited. 
2009, 810), a major focus often falls on 14-16-year-olds. Until 2012 in England, government guidelines for work-related learning (WRL) for students in key stage four (14-16) encouraged many local authorities (LAs) to address disengagement through vocational learning (DfES 2006). Indeed, As Avis, Fisher and Ollin (2010, 48) point out, 'Work-based learning has been central to government policy since New Labour's election in 1997 and constitutes a substantial proportion of vocational education and training.' Moreover, many disaffected students exercise their right to disengage and choose to undertake alternative options, and as Davies and Biesta $(2007,32)$ suggest, choice is often influenced by 'attitude towards school.'

This research, then, examines the relationship between attitude and disengagement. It explores the impact of WRL on disaffected students' attitudes to learning in a small, urbanized borough in the north of England (referred to as Newtown). Specifically, the research asks: i) How does vocational learning affect disaffected students' attitudes to learning? ii) How does attitudinal change impact on disaffection with school? In light of recent legislation in England to further raise the participation age to 18 by 2015 (Gov.UK 2014), and the claim that 'disengaged young people are far less likely to aspire to continue with full time education' (Ross 2009), this age range is viewed as a critical period.

Newtown is an area that exhibits pockets of social deprivation, relatively high unemployment rates, and comparatively poor general health. According to a recent census, its ethnic constitution is predominantly white and the ratio of females to males is 1.1:1 respectively. Although GCSE achievement has increased in recent years, there remains a concern of underperformance in relation to the national average. Consequently, the LA advocates addressing disaffection in 14-16-year-olds through its work-based learning programme (WBLP) - a variety of private training providers offering alternative learning in subjects such as construction, hair and beauty, motor vehicle maintenance, and sports. Schools value the WBLP for its engagement potential and it is often used as a mechanism for exclusion avoidance.

Students are referred to the programme when their school deems them to be disaffected. Thus, the term disaffection in this paper refers to the school use wherein students reach a level of dissatisfaction with learning and are seen to actively disengage. Schools attribute such actions to poor attendance, unacceptable behaviour, and vulnerability, and these can be influenced by 'gender, social class, location, disability and ethnicity' (James and Simmons 2007, 367). As such, those who are 'quietly disaffected' may fall beneath the radar of support (Feng and Jament 2009).

The WBLP was established in 2002 to improve key stage 4 engagement and reduce the number of individuals deemed to be NEET (not in education, employment or training). The programme acts as an interface between school and the workplace and students can attend for one to five days per week in a provider of their choice. ${ }^{\mathrm{a}}$ Although the term WBL is used, students mostly engage in WRL and providers vary from actual workplaces to simulated working environments. The positive impact of the programme for schools is an increase in attendance and qualification achievements (see Allan 2014). However, attendance on the WBLP has led to a problematizing of attitudes to learning in school. Thus, while WBL can offer 'a clean slate for disengaged students' (Kelly and Price 2009, 819), their return to school often results in a magnification of the causes of their initial disaffection. 


\section{Context}

\section{Vocational learning}

Forms of vocational learning have often been employed as an alternative route for disengaged young people (Thomson and Russell 2009). Hall and Raffo (2004, 73), for instance, claim that industry training and experiences of the real world can be 'motivational' and can benefit disaffected young peoples' attitudes to school, while Kyndt and Baert (2013) suggest that attitudes to WRL are related to learning intention. Thus, attitude is conceptualised as a crucial factor in disaffection in that it is related to choice, whereby disengagement is arguably an agentic student action. Furthermore, education needs to be valued by young people (Fuller and Macfadyen 2012), and this can impact on attitude and, subsequently, engagement.

In England, post-14 education has been broadened to include further education colleges (DfE 2013) while vocational learning has been reformed to meet the needs of higher education (Wolf 2011). Consequently, the cores of engagement/re-engagement and WBL are often manacled together to illustrate correlation. Raffo $(2003,69)$ for instance posits WBL as offering an 'alternative curricula [for] re-motivating and re-engaging those young people classified as being 'at risk' or disaffected.' Moreover, the rapid growth in vocational awards taken in recent years has resulted in greater recognition for vocational learning and it now makes 'far greater contributions to performance measures' (Wolf 2011, 48). However, teaching standards vary widely and 'a key problem for vocational education curriculum and pedagogy [is that a] perception persists that it only needs to account for low levels of outcomes' (Billett 2003, 7).

Kyndt \& Baert $(2013,275)$ draw on Martin Fishbein and Icek Ajzen's theory of reasoned action to explain the rise of a students' educational need, whereby 'behaviors are steered by their intentions that are, in turn, shaped by their perceptions and considerations of various personal, social, and contextual factors.' Thus, vocational learning can hold appeal for some students in that there is a link to the working world and therefore a perceived requirement. As such, it can be a mechanism for acquiring, and engaging in, significant cultural and social practices (Virtanen et al. 2014) and may therefore play a role in shaping attitude. In this way, the students bring experiences to an environment where learning 'builds on...tacit knowledge [and] is likely to lead to increasing competence as it regards people as knowledge-rich rather than suffering from a skills-deficit' (Ahlgren and Tett 2010, 26). Along with social interaction and engagement in work-related activities then, the workplace culture can shape identity and change a deficit learning discourse to one of strengths (Ahlgren and Tett 2010) as it impacts on attitudes to learning (Kyndt and Baert 2013).

The choice to engage in vocational learning is dependent on attitude (Davies and Biesta 2007). It can give rise to a work identity that is strongly connected with learning and situation (Bentley 1999; Klotz et al. 2014) and is argued as being 'mediated by individuals' subjectivities' (Billett 2006, 2). As such, Raelin $(2010,39)$ suggests that WBL 'merges theory with practice and acknowledges the intersection of explicit and tacit forms of knowing.' Moreover, Harris et al. (2001, 270) identified apprentices' perceptions of learning, claiming it 'just happened' through involvement with the task in hand. In this way, a strong learner-task relationship, along with attributed relevance, may lead to a tacit acquisition of skills. Thus, working and learning can be perceived similarly in terms of motivation, achievement and attitude towards tasks as students' interests are often related to occupation (Schmitt et al. 2008). 


\section{Environment: engagement or ennui?}

Learning in a mature environment can result in greater autonomy and enhanced metacognition (Smith 2003) while attitudes to work often show improvement when learning is undertaken in a workplace context (Zemblyas 2006), particularly if the workplace is regarded as expansive (see Fuller et al. 2007). However, where existing relationships with schools are strained, poor connotations of school values can be perpetuated and participation in some forms of work-related learning can 'exacerbate inequality, poverty and social dislocation' (Simmons 2009, 138).

Konkola et al. $(2007,213)$ state that 'knowledge is not only mentally structured but fundamentally bound to particular situations', while Ahlgren and Tett (2010, 24) note: 'learner identity and workplace culture interact to facilitate or close down opportunities for learning and development.' Thus, attitudes to learning can be ambient specific which may pose difficulties for teachers when supporting disengaged students. Consequently, the experience of an alternative environment can result in students' poor attitudes to school becoming negatively reinforced (Hall and Raffo 2004), particularly if the engagement potential of the vocational learning is that it merely offers a 'different' environment (Davies and Biesta 2007).

Furthermore, Simmons $(2009,137)$ argues that low-level WBL can perpetuate socialclass divisions as it often produces 'an impoverished form of employability', and Thompson (2010, 135) suggests that there are often socioeconomic implications for learners in this situation as 'limited resources and a lack of progression opportunities are...'woven into' their lives' (Thompson 2010, 135). So-called transferable skills, then, may have limited transferable capital whereupon students may struggle to progress to other forms of employment, such as apprenticeships. In this way, the students are 'denied access to a relational understanding and the capacity to generate new knowledge' (Simmons 2009, 148). Schools argue, however, that while students may not be re-engaged in school, they are at least engaged in some form of learning when attending a vocational learning provider.

\section{Work-related learning in schools}

Between 2004 and 2012, schools in England were required to provide work-related, and enterprise, learning for all students at key stage 4 (DfES 2006) and through this many disaffected 14-16-year-olds secured engagement (Hall and Raffo 2004; Raffo 2003). Arguably, this initiative was reconstituted from previous claims of the necessity to develop the economy through the creation of a varied workforce (Jamieson 1993) and to address 'low levels of productivity' (Cuddy and Leney 2005, 15). However, this does not include the many cultural restraints. Students from families of third-generation unemployment often display signs of negative socialization and a poor outlook that can constrain progress (McKendrick et al. 2007; Sodha and Guglielmi 2009). Implementing WRL in schools, therefore, is not without challenge.

GCSEs generally take precedence in the UK and deeply rooted in the education system is a majority belief that vocational education is inferior to academic learning (Hyland and Winch 2007). In 1996, the Dearing report (Dearing 1996) contested this assumption and proposed major changes in the education system to create parity, such as stronger links between HEIs and industry. More than a decade later, the introduction of Diplomas appeared to challenge such qualification inequality 
(Hodgson and Spours 2008) yet vocational teachers still suffered discrimination (Thompson 2010) and vocational education retained its 'much lower status than more traditional and academic routes' (Fuller and Macfadyen 2012, 87). Over the last 30 years in England, successive governments have attempted to redress the balance and gain parity of status by introducing a variety of vocational qualifications (Wolf 2011). Indeed, the Department for Education is now looking to include more vocational subjects in the 2016 key stage 4 performance tables (see DfE 2014) in the belief that they can add dynamism and diversity to learning by complementing employment and/or developing the skills and ability to secure it. However, it is important that such vocational learning retains credence as low-level WBL - often used to pay lip service to disaffection - can perpetuate the gulf.

In order to bridge the academic-vocational divide, Bentley's $(1999,112)$ suggestion that 'forms of learning outside the conventional classroom and subject framework must be connected fully to the pursuit of conventional qualifications' seems pertinent. This gulf between the working world and the base educational establishment is important and can go far to suggest reasons for the reinforcement of negative attitudes to school when some learners experience work. Indeed, many would argue that schools in the $21^{\text {st }}$ century are not meeting the varied needs of their pupils and Diplomas were arguably another example of the 'historic weaknesses in the provision of work-based education and training for young people [in the] English education and training system' (Hodgson and Spours 2010, 95).

\section{Work and learning: the successful merger}

During the early years of a student's learning, there appears to be an inculcation of concepts of work and societal status that are arguably embedded by key stage four. Saunders $(2006,4)$, for instance, notes 'a continuation of highly differentiated cultural meanings developed through family, community and peer group.' Furthermore, working-class attitudes are often influenced by middle-class subjectivities (Reay 2001) and a yearning to acquire cultural capital (see Bourdieu and Passeron 2000). Thus, socialization may contribute to learners' acceptance of WRL. However, cultural influences can also lead to a 'scholastic counterculture' (Humphrey et al. 2004, 592 ) where school is rejected (although young people are 'capable of exerting a marked influence over their own development' (Schaffer 2006, xiv)).

For WRL, then, there may be a perceived relevance as learners connect with an alternative form of cultural capital; one where social mobility is experienced through the acquisition of industry-related knowledge. Liaising with real people in a supposedly real industry can mean undertaking tasks that are deemed to be relevant. Consequently, a realistic objective, such as working towards paid employment, can impact on attitudes to learning and promote engagement, i.e., students embrace opportunities to undertake practical learning activities and reject school (Hall and Raffo 2004).

The students in this study show that attitudes to learning are often related to environment and subject relevance, where environment plays a crucial, and often overriding, influence. Furthermore, as noted earlier, attitudes to learning can influence choice (Davies and Biesta 2007) and thus potentially result in disengagement. 


\section{Assessing attitudes}

Assessing students' attitudes can be conducted using a number of approaches and will often be either qualitative or quantitative. Deciding on which approach depends on the research design and the epistemological assumptions made prior to the research (Gall et al. 1996). Lovelace and Brickman $(2013,606 / 7)$ argue for a quantitative approach, suggesting that for qualitative research, 'analyzing written comments or transcripts can be labor intensive [while] quantitative analysis tools...allow for easier compilation of student responses.' However, I have adopted a mixed-methods approach for this research in order to triangulate the data in a way that differs to that when a single approach is taken. Thus, this study utilises both quantitative and qualitative data - with a weighting of around 70 to 30 per cent respectively. Qualitative data are used to add depth to the phenomenon and to triangulate the findings (Ritchie and Ormston 2014).

Popular means of assessing students' attitudes include the psychological approach (often positivist), such as psychometric testing, and the interpretivist approach (e.g. from a social constructionist's perspective). Through the psychological approach, there are many standardised surveys and questionnaires - tried, tested, and sanctioned by scholars - that are used to capture a student's current attitude to learning (see Lovelace and Brickman 2013). The attitudinal survey, for instance, is often used to acquire a large number of responses and asks students to respond to statements or answer questions that they feel most appropriately represents their situation and mindset. These tests may be undertaken more than once in an academic year as this increases the reliability of the assessment mechanism and illustrates changes in thinking.

From a social constructionist approach (see Burr 1995), attitudes are captured through methods such as interviews as these allow the researcher to explore the interviewee's current perception, to clarify issues (Slater et al. 2011), and to obtain in-depth qualitative data. In their study, Sandal et al. (2014) use focus group interviews to obtain a student voice that represents motivation and attitudes to vocational learning. This approach is significant for their research in that it identifies varied assessment cultures between school and a vocational learning environment. However, a quantitative approach is also an effective means of conducting cross-environmental research as it enables the targeting of a broader sample of participants. Swift and Fisher (2012), for instance, undertook a questionnaire survey with 197 students from schools and colleges to capture their perceptions of education and training. However, the authors recognised that a mixture of methods can present new findings; thus, the survey was followed by semistructured interviews to draw out some of the nuances of the responses.

\section{Methods}

For the present study, the attitudes of a random selection of 30 disaffected school pupils were investigated. Attitudes are scored subjectively by professionals (teachers and tutors) using the Newtown Student Profile (NSP) (see Table 1).

In consultation with a nearby university, the NSP was devised by schools and the local authority of Newtown and draws on a range of features from psychological and sociocultural perspectives on attitudes to learning. The assessment procedure utilises a practitioner approach to student attitude and thus draws on the practical pedagogical experiences of teaching professionals. Attitudinal categories were therefore identified 
Table 1 Newtown Student Profile

\begin{tabular}{|c|c|c|c|c|}
\hline \multicolumn{5}{|c|}{$\begin{array}{l}\text { Please circle a rating for the student using the following scale: } 1 \text { Very poor, } 2 \text { Satisfactory, } 3 \text { Good, } 4 \\
\text { Very good }\end{array}$} \\
\hline \multicolumn{5}{|l|}{ General attitude } \\
\hline Confidence & 1 & 2 & 3 & 4 \\
\hline Conformity & 1 & 2 & 3 & 4 \\
\hline Alertness & 1 & 2 & 3 & 4 \\
\hline Wish to impress & 1 & 2 & 3 & 4 \\
\hline Punctuality & 1 & 2 & 3 & 4 \\
\hline \multicolumn{5}{|c|}{ Workplace/Classroom behaviour } \\
\hline Comfort level & 1 & 2 & 3 & 4 \\
\hline Response & 1 & 2 & 3 & 4 \\
\hline Concentration & 1 & 2 & 3 & 4 \\
\hline Self-control & 1 & 2 & 3 & 4 \\
\hline Ability to work alone & 1 & 2 & 3 & 4 \\
\hline Ability to work in a team & 1 & 2 & 3 & 4 \\
\hline Overall engagement & 1 & 2 & 3 & 4 \\
\hline \multicolumn{5}{|l|}{ Attitude to teacher/tutor } \\
\hline Ability to follow instructions & 1 & 2 & 3 & 4 \\
\hline Interest level & 1 & 2 & 3 & 4 \\
\hline Co-operation & 1 & 2 & 3 & 4 \\
\hline Completion of tasks & 1 & 2 & 3 & 4 \\
\hline \multicolumn{5}{|l|}{ Attitude to peers } \\
\hline Composure & 1 & 2 & 3 & 4 \\
\hline Interest level & 1 & 2 & 3 & 4 \\
\hline Helpfulness & 1 & 2 & 3 & 4 \\
\hline Patience & 1 & 2 & 3 & 4 \\
\hline
\end{tabular}

using a mixture of existing surveys and collaborative pedagogical knowledge. The profile is used to measure students' attitudes and focuses on the following areas: General Attitude, Workplace/Classroom Behaviour, Attitude to Teacher/Tutor, and Attitude to Peers. These constructs were identified as being particularly relevant for students in Newtown and arose from an earlier survey, conducted by the LA, into teachers' perspectives on attitudinal concerns. Moreover, reflecting on their professional experiences of several years of working with disaffected students in Newtown, staff in many of the providers also support the suggestion that these are the most pertinent areas for attitudinal measurement. These constructs are also relevant for this study as they reflect levels of disengagement/engagement.

The profiles contain a scoring system from 1 to 4 whereby 1 represents an extreme negative and 4 an extreme positive and each category has a series of subcategories. The tutor recording the grade undertakes a subjective assessment of each student, based on their perception of the student's conduct and attitude in the specific environment. The same tutor then reassesses each student at the end of the academic year. Although this system of measuring can introduce unwanted variables (see research limitations), it is accepted as a consistent mechanism of recording data due to the inter-rater reliability testing conducted by the researcher. 
The teachers performing the assessments were described by the head teacher as capable, motivated, and very supportive when dealing with disengaged students. Moreover, they have also previously taught many of the pupils in the three years leading up to the research; therefore, relationships between teachers and students may be somewhat different to those in the WBL provider (see research limitations). However, the research does not compare the scoring system of a teacher with a tutor; rather, beginning and end profiles are analysed comparatively by institution.

All 30 students were in year 10, were on the verge of exclusion from school, and were allocated to the WBLP. In order to keep variables to a minimum, and in an attempt to illustrate a non-biased gender representation, the sample comprised 15 boys and 15 girls. All students were white, had been born and raised in Newtown, and were identified as working class as they were registered for free school meals. Each student has four profiles, two from their school and two from a WBL provider. The school completed a profile before the students commenced their study (September) and another when they returned in July, and WBL provider staff completed one in the first week of study (late September) and one before they left in July. The particular aspects of attitude measured were in relation to learners towards: their peers, staff members, their environment, and tasks they were allocated.

\section{Inter-rater reliability}

Prior to the recording of student scores, all tutors were asked to observe a sample of students undertaking an activity and to provide a rating for attitude and behaviour for each student. Discrepancies in scoring were discussed before the observation and the tutors agreed on standard criteria for measuring (see research limitations). The ratings were then analysed for internal reliability using Cronbach's alpha, wherein a calculated coefficient of 0.812 was recorded.

\section{Interviews}

In addition to the profiles, 10 of the 30 pupils were interviewed for triangulation. This group was also balanced by gender (i.e. five boys, five girls) and participants were again chosen at random. The interviews were semi-structured and informal, and focused on the participants' attitudes to learning and impressions of each environment. They were conducted in September and again in July of the same academic year and each one lasted between 20 and 30 minutes. Interviews were transcribed and coded before being subjected to a thematic analysis, based on Radnor's (2002) framework. 'Patterns and clusters of meaning' (Ritchie and Ormston 2014, 271) were drawn from the data that related to the students' attitudes to learning and several codes were thus identified.

Although this process relies on an interpretivist approach, the codes were reexamined in relation to the quantitative data to ascertain proximity to the research questions and provide an arguably meaningful interpretation of the interview data. Thus, while the larger focus of the study lay on the quantitative analysis, the interview data were used to provide triangulation. Themes were identified through the interview data's relation to the scoring system data so that all could be comparatively analysed. From the interviews, attitudes were found to be strongly consistent with the subjective 
Table 2 Work-based learning provider

\begin{tabular}{|c|c|c|c|c|c|c|c|}
\hline \multicolumn{8}{|l|}{ General attitude } \\
\hline Differential & -3 & -2 & -1 & 0 & +1 & +2 & +3 \\
\hline Confidence & 0 & 0 & 0 & 4 & 7 & 17 & 2 \\
\hline Conformity & 0 & 1 & 2 & 5 & 7 & 9 & 6 \\
\hline Alertness & 0 & 0 & 1 & 13 & 10 & 5 & 1 \\
\hline Wish to impress & 0 & 0 & 2 & 5 & 10 & 10 & 3 \\
\hline Punctuality & 0 & 1 & 2 & 10 & 11 & 4 & 2 \\
\hline \multicolumn{8}{|l|}{ Workplace behaviour } \\
\hline Differential & -3 & -2 & -1 & 0 & +1 & +2 & +3 \\
\hline Comfort level & 0 & 0 & 4 & 11 & 9 & 5 & 1 \\
\hline Response & 0 & 0 & 2 & 9 & 9 & 9 & 1 \\
\hline Concentration & 0 & 2 & 0 & 10 & 8 & 9 & 1 \\
\hline Self-control & 0 & 1 & 3 & 5 & 10 & 11 & 0 \\
\hline Ability to work alone & 0 & 1 & 2 & 2 & 10 & 12 & 3 \\
\hline Ability to work in a team & 0 & 3 & 3 & 7 & 6 & 9 & 2 \\
\hline Overall engagement & 0 & 1 & 2 & 0 & 14 & 8 & 5 \\
\hline \multicolumn{8}{|l|}{ Attitude to tutor/mentor } \\
\hline Differential & -3 & -2 & -1 & 0 & +1 & +2 & +3 \\
\hline Ability to follow instructions & 0 & 2 & 8 & 7 & 11 & 1 & 1 \\
\hline Interest level & 1 & 4 & 4 & 3 & 10 & 6 & 2 \\
\hline Co-operation & 1 & 1 & 3 & 8 & 11 & 5 & 1 \\
\hline Completion of tasks & 2 & 0 & 2 & 5 & 9 & 10 & 2 \\
\hline \multicolumn{8}{|l|}{ Attitude to peers } \\
\hline Differential & -3 & -2 & -1 & 0 & +1 & +2 & +3 \\
\hline Composure & 0 & 3 & 7 & 8 & 7 & 4 & 1 \\
\hline Interest level & 0 & 0 & 9 & 8 & 6 & 4 & 3 \\
\hline Helpfulness & 0 & 0 & 1 & 3 & 7 & 15 & 4 \\
\hline Patience & 1 & 0 & 3 & 10 & 8 & 6 & 2 \\
\hline Total & 5 & 20 & 60 & 133 & 180 & 159 & 43 \\
\hline
\end{tabular}

scoring of the teachers and tutors and data are used here to substantiate this. All participants were anonymised in the data recording process.

\section{Results and discussion}

The difference in values between the beginning of the academic year (Table 2) and the end of the academic year (Table 3) is represented below.

A figure is provided for the number of students whose attitudes have either improved or deteriorated, and ratings that remain the same are recorded as zero. Thus, the tables illustrate changes in ratings and both tables can be viewed in comparison in the condensation tables ( 4 and 5 ).

\section{Total results in comparison}

Tables 2 and 3 illustrate the particular aspects of attitude that have improved or worsened while Tables 4 and 5 illustrate the totals for the differentials, thus 
Table 3 School

\begin{tabular}{|c|c|c|c|c|c|c|c|}
\hline \multicolumn{8}{|l|}{ General attitude } \\
\hline Differential & -3 & -2 & -1 & 0 & +1 & +2 & +3 \\
\hline Confidence & 0 & 0 & 2 & 9 & 12 & 6 & 1 \\
\hline Conformity & 0 & 2 & 9 & 13 & 6 & 0 & 0 \\
\hline Alertness & 0 & 3 & 9 & 8 & 5 & 5 & 0 \\
\hline Wish to impress & 0 & 1 & 12 & 13 & 1 & 3 & 0 \\
\hline Punctuality & 0 & 2 & 10 & 9 & 6 & 1 & 2 \\
\hline \multicolumn{8}{|l|}{ Classroom behaviour } \\
\hline Differential & -3 & -2 & -1 & 0 & +1 & +2 & +3 \\
\hline Comfort level & 0 & 3 & 6 & 11 & 9 & 1 & 0 \\
\hline Response & 0 & 1 & 14 & 10 & 4 & 1 & 0 \\
\hline Concentration & 0 & 4 & 9 & 9 & 4 & 3 & 1 \\
\hline Self-control & 0 & 2 & 7 & 14 & 6 & 1 & 0 \\
\hline Ability to work alone & 0 & 4 & 5 & 9 & 11 & 1 & 0 \\
\hline Ability to work in a team & 0 & 1 & 5 & 9 & 13 & 2 & 0 \\
\hline Overall engagement & 0 & 4 & 14 & 9 & 3 & 0 & 0 \\
\hline \multicolumn{8}{|l|}{ Attitude to teacher } \\
\hline Differential & -3 & -2 & -1 & 0 & +1 & +2 & +3 \\
\hline Ability to follow instructions & 0 & 1 & 7 & 7 & 12 & 3 & 0 \\
\hline Interest level & 0 & 2 & 9 & 7 & 8 & 4 & 0 \\
\hline Co-operation & 0 & 7 & 13 & 5 & 3 & 2 & 0 \\
\hline Completion of tasks & 0 & 5 & 10 & 15 & 0 & 0 & 0 \\
\hline \multicolumn{8}{|l|}{ Attitude to peers } \\
\hline Differential & -3 & -2 & -1 & 0 & +1 & +2 & +3 \\
\hline Composure & 0 & 2 & 8 & 14 & 6 & 0 & 0 \\
\hline Interest level & 0 & 3 & 16 & 11 & 0 & 0 & 0 \\
\hline Helpfulness & 1 & 0 & 9 & 15 & 4 & 1 & 0 \\
\hline Patience & 1 & 4 & 11 & 6 & 8 & 0 & 0 \\
\hline Total & 2 & 51 & 185 & 203 & 121 & 34 & 4 \\
\hline
\end{tabular}

providing a snapshot of the overall impact of change. These tables suggest that the experience of WBL creates engagement in the provider as it aids in improving students' attitudes to learning; however, this results in negatively reinforced impressions of school. Furthermore, attitudes to school were interpreted as particularly negative where students attended WBL for five days.

\section{The environment factor}

Overall, attitude levels improve as learners respond positively to the WBL provider and this appears to impact on engagement. Specifically in the context of school however, there is significant attitude deterioration. Pupils' impressions of school become negatively reinforced as they embrace the environment of the provider; thus, the WBLP can promote engagement in learning but further disengagement with school. Evidently, maintaining strong pupil-school connections throughout the alternative learning experience is a significant factor in improving students' attitudes. In this way, attitude and 
Table 4 Work-based learning provider

\begin{tabular}{llllllll}
\hline Differential & -3 & -2 & -1 & 0 & +1 & +2 & +3 \\
\hline Total & 5 & 20 & 60 & 133 & 180 & 159 & 43 \\
\hline
\end{tabular}

engagement are interrelated, as can be seen in an example by Anthony who agreed to return to school to catch up on his work: 'I used to hate school but now it doesn't bother me. I don't mind going to do me maths and English for one day so long as I can come here [WBL provider] for the rest of the week.' Thus, Anthony's engagement with the provider has impacted on his attitude to school whereupon he is able to reconnect with learning.

Complementing the profiles, the interviews helped to ascertain whether the qualitative aspect of the study reflected the quantitative data. Learners commented on the environment of their workplace learning and around $90 \%$ stated that they felt that they were treated in a more mature manner. Sophie explains: 'It's just...the way they [WBLP tutors] speak to you. They understand you. And they don't, like, talk down to you like they do in school.'

\section{School versus work-based learning}

Some students attended both school and a WBL provider whilst others were educated off site for five days and this variable produced interesting results. Out of 30 students, 18 were eventually allocated to WBL for the full five days by December of that academic year and continued with this programme of study until the end of their compulsory education. Although students are supposed to return to school near the end of the academic year, only a small number attended regularly due to a tacit school assumption (or wish) that they remain off site. Subsequently, very little support was offered for any formal reintegration and schools often argued that it was detrimental to the students' studies to cease the programme early. Thus, many re-engaged in learning but not in school. As Abbey explains, 'I just want to get me head down now and get on with it. But they [school] won't let me back in.' Consequently, Abbey's attitude to school deteriorates further as she is forced to remain disengaged from this environment. Towards the provider, however, her engagement deepens as her attitude improves and this facilitates a reconceptualising of learning where WBL is accepted and school is rejected.

For those students who find the WBLP to be unsuitable, alternative learning programmes can be trialled, such as outdoor pursuits. If these prove unsuccessful, however, students are excluded. Consequently, and arguably tragically, the legal process of pursuing non-attendance is so complicated and drawn out that issues in year 11 can remain unresolved at the end of the academic year. Perhaps understandably, it is evident that those who were not allowed back into school - even one day per week - displayed the greatest aversion to the school system. Thomas was working towards a level one certificate in motor vehicle studies and expressed his view of school: 'I'm glad they won't have me back; I can't stand the place. All we used to do was copy out of a book. What's the point?'

Table 5 School

\begin{tabular}{llllllll}
\hline Differential & -3 & -2 & -1 & 0 & +1 & +2 & +3 \\
\hline Total & 2 & 51 & 185 & 203 & 121 & 34 & 4 \\
\hline
\end{tabular}


Table 6 Varied attendance

\begin{tabular}{lcll}
\hline Attendance at provider only (18 students) & & \\
\hline Positive attitude toward provider & 17 & Positive attitude toward school & 1 \\
Attendance at provider and school (12 students) & & \\
Positive attitude toward provider & 5 & Positive attitude toward school & 7 \\
\hline
\end{tabular}

\section{Profile analysis for overall attitude}

Table 6 shows the overall rating for improvement in attitude throughout the academic year for the students and differentiates between the 12 that accessed school and the 18 that did not. From this we can glean the varying attitudes towards the differing educational provision for the five-day students.

Seventeen of the above 18 students scored negatively towards school yet were rated highly by the provider. The students adapted to their new environment whilst simultaneously dissociating further from their old one: 'I hated school. I couldn't get into it. I don't know why I stayed there so long, to be honest. There's no way I'd go back' (John). As such, teachers' ratings may have been influenced by strained prior relationships and a perception of reduced disruptions during the student's absence; moreover, the need to be educated off site for five days per week could be indicative of students having greater initial problems than those who 'tolerated' school. However, a Dependent $t$-test was conducted on the General Attitude to investigate the effect of the independent variable (WBLP). For schools, General Attitude was found to be significantly higher for July $(M=2.0, \mathrm{SD}=.23)$, compared to September $(M=1.62$, SD $=1.30 ; t(11)=-2.57, \mathrm{p}$ $<.05)$. For providers, General Attitude was also higher in July $(M=2.89, \mathrm{SD}=.21)$, than September $(M=1.77, \mathrm{SD}=1.29 ; t(11)=-3.1, \mathrm{p}<.05)$.

Those who were allowed to return to school appeared to benefit from the academic support as the providers mostly focused on the development of vocational ability. Combining the two environments, therefore, developed both vocational and academic skills and helped to improve attitudes towards members of staff in the school. Thus, attitudes have shown the greatest improvement towards school in the learners who attended a WBL provider alongside their schooling. In this way, the interplay between attitude and engagement illustrates that some students are willing to reconceptualise school once they are engaged. Bethany, for example, is studying hair and beauty and is generally happy with her school progress: 'I did have a bad time for a while but it's all right now. There are still some teachers I stay away from but I don't hate them...I just avoid them. I'm only in two days. And the others are good...they let me do my [provider] portfolio sometimes.'

Students attending five days per week in a training provider improved their overall attitudes towards the provider considerably - with high scores towards peers and staff yet their attitudes towards school deteriorated. School profiles show little or no attitudinal improvement and students illustrate a growing aversion to the school system. As Henry stated, 'John [provider tutor] listens to you; he's brilliant. I never had that at school. I just got sent out all the time. There's no way I'd go back. I didn't realise how bad it was until I got out.' This impression can also be found in the attitude to teachers/tutors, with an overall score of 54 negative points recorded at school $(-1$ and below) compared to 28 at the WBL provider (see Tables 3 and 4). 


\section{Attitudes to environment}

The data show that disaffected students' attitudes to learning in general improve when they undertake WRL and improve towards school when the students attend school alongside the WBLP. However, positive attitudes towards school dramatically reduce when students solely attend a provider. Thus, school connection functions as a complication in the interrelationship between attitude and engagement, whereupon students re-evaluate their social position and no longer perceive themselves as school pupils.

John: 'As far as I'm concerned, I've left school.'

Interviewer: 'What about next year?'

John: 'I'll just stay here.'

Interviewer: 'What happens if they won't let you?'

John: 'I'll just stay off - I'm not going back'

Attitudes towards the providers increase in almost $75 \%$ of cases and breaking the link with the school does appear to have a significantly negative effect.

The majority of the WBL providers in this study exercised a relaxed, even casual, approach and this enabled the students to draw on some of the informal aspects of learning, such as the learning that can occur through colleague interaction and involvement in an activity (Felstead et al. 2005; Harris et al. 2001). As Steve explains, 'We have a laugh but we learn things. Sometimes we have a task to do so we do it together. I like that because if I don't know something then someone else will. It's better than having some teacher waffle on at you.' Knowledge application was embraced by the learners; in particular, the encouragement of practical activities where academicism could be inculcated.

'I like doing things where I can see what I've done at the end of it - like colouring hair. You know when you get it right...and it makes you feel good. For me, that's learning because I can use it again' (Emma).

Students claimed that working practically enabled them to see the relevance of the task in hand. As Abbey points out, 'I love learning about styling and working with clients but I'm not good at reading. I hate sitting in class.' Even though writing was considered 'boring', WBL tutors reported above-average success in the completion of portfolios where there was a connection to the practical element.

\section{Returning to school}

The WBLP has been shown to be beneficial for engaging students in learning and impacting positively on their attitudes. However, the negative reinforcement of school values is somewhat problematic. Many learners in year 10 embrace the new environment yet maintain resentment towards school and this is further complicated when they are deemed eligible for re-entry. In many instances in this study, young people returning to school illustrated further disaffection. Out of the overall scoring, the provider illustrated 382 positive ratings and 85 negative ones (Table 4). School, however, (Table 5) identifies only 159 positive ratings compared to 238 negative recordings. Clearly, the change in environment had engaged these students yet simultaneously altered their attitudes as it strengthened their view that the school was the cause 
of their initial disaffection. Mike, who studied construction, commented on his school experience: 'We never did anything. It was boring! The teachers used to shout at us all the time and we just took the $\mathrm{p}^{* * * *}$. I was always getting sent out. You don't learn anything.' In the WBL provider, Mike was halfway through a level one in construction at the end of year 10 and completed it in year 11. He used this to attend college.

Even though many attitudes towards school had declined over the academic year, we can see improvement in some aspects, such as attitudes towards the teacher in relation to completing tasks (Table 3). In the interviews, many students expressed a preference for engaging with learning that reflected their vocational interests (Schmitt et al. 2008) and this supports the claim that an intention to learn is related to attitudes to WRL (Kyndt and Baert 2013). As such, the interview data and the attitudinal findings from the profiles evidence commonality. Consequently, some students will engage further if a learning connection is made. For instance, literacy and numeracy uptake increased when these subjects were linked to WBL, such as calculating the number of bricks required, or the ratio of chemicals in hair products. Jenna explains how she felt:

'I hate maths normally, but that [calculating] was all right. We had to add up all the takings and take it off the float that we got at the start. And we had to work out how to take $25 \%$ off for students. It was good, I enjoyed it.'

Since the majority of learners on the WBLP have either been excluded or are at risk of exclusion, WBL providers aim to re-engage as well as facilitate development in vocational areas.

Attitudinal improvement may result from the combination of individual student attention and an initial focus on engagement. Therefore, the argument that attitude influences choice (Davies and Biesta 2007) suggests that some students are choosing to engage. However, while the majority of the students evidenced increased motivation, some refused to engage or illustrated needs beyond the remit of the WBLP. Thus, motivating disaffected students is complex and WBL may only form one strand of a larger re-engagement strategy.

\section{Research limitations}

The research design for this study exhibits two limitations. First, subjective scoring is not the most efficient manner of recording data yet it can give an adequate level of consistency if the same raters are used and criteria for measuring are agreed in advance. The data collection is open to many variables - such as tutor preference and perception (although Cronbach's alpha is used to increase inter-rater consistency) - and this was considered with the interpretive account of the findings. For example, some providers may wish to impress schools with impeccable re-engagement and teachers could be influenced by previous scoring. Therefore, interviews are used to validate the data. Even though only ten were conducted for this research, the qualitative aspect gained from these was deemed to be more than sufficient to triangulate the data as the interviews allowed for depth of responses. The research sample on the whole is perhaps comparatively small yet I argue that the data is rich as it is captured at two periods and interviews complement the profile scoring. In many ways this research is supportive of the literature yet it also identifies an interplay between attitude and engagement. As such, the study provides a foundation for further research. Generalizations can only be drawn with a view to further exploration and this is perhaps more reflective of qualitative research. 
Second, although the research uses an equal number of males and females, there is no in-depth analysis of gender. The primary reason for this is that the students display overarching disconnection from compulsory education (in particular, from school practice) and gender-based causes of disaffection are considered to be another study per se. An equal split was chosen to support the hypothesis that disaffected states are not necessarily gender specific.

\section{Conclusions}

The findings for the impact of vocational learning on students' attitudes is arguably important for school policy as attitudes can influence learning choices (Davies and Biesta 2007), wherein a student may choose to disengage, and choice in itself has been noted as one of the 'key elements of vocational education [for] improv[ing] students' social psychological adjustment to school' (Kelly and Price 2009, 812). As such, many aspects of this research concur with similar studies (e.g. Hall and Raffo 2004), and support previous research into the impact of vocational learning programmes on disaffection (Raffo 2003; Kelly and Price 2009) and qualification achievement (Allan 2014). However, even though many of these students' problems appertain to the school environment and its practices, sole engagement on the WBLP can have further deleterious effects; in particular, attitudes to school can worsen.

Furthermore, those attending five days per week display a growing inclination to pursue vocational learning. However, where engagement is sought through low-level WBL, pupils may incur further exclusionary practices whereby more purposeful post-16 options are unattainable. Thus, movement away from the school environment may result in a permanent alternative route and although there can be many benefits to WBL, some 'do not readily transfer to school-based settings' (Hall and Raffo 2004, 71).

The data illustrate disaffected students' attitudes to varying environments and the complexity of engagement/re-engagement in 14-16-year-olds. We have seen that attitudes improve in the environment of the WBL provider but primarily towards that provider and its workplace and that they fare higher when the student does not attend school at all. Thus, the attitude-engagement interplay illustrates that these students' attitudes towards each environment vary, depending on levels of engagement. From students' non-attendance at school I have inferred a propensity towards a negative reinforcement of poor school perceptions. These students appear convinced that they have chosen the most suitable path and that traditional schooling is not for them.

Where the student has attended school for one day or more, there has been less of a rise in positive attitude in the provider but an increase in acceptance of the school system and this is an important finding for schools. Opportunities to access learning in a wider context, then, are dependent on strong connections with school (Bentley 1999). Combined with this is the benefit of academic improvement that school facilitates as providers admit that they are not equipped to teach English and maths to the level of an academic institution. Thus, in order to impact on disaffection, vocational learning is used to improve attitudes to learning with the effect of reengagement in school emanating from a student's choice to participate (Davies and Biesta 2007). This is important as young people need to value their learning (Fuller 
and Macfadyen 2012). School disaffection, then, can reduce through the opportunity for students to experience alternative learning where school links are maintained.

In addition to WRL's potential to address disaffection, there are many social benefits. A work environment can provide an opportunity for students to socially reintegrate when they have been marginalised, providing that they are not attending solely as somewhere 'different' to school (Davies and Biesta 2007) and not engaging in low-level WRL where 'inequality is reconfigured and reproduced' (Simmons 2009, 148). Furthermore, as some forms of vocational engagement may not lead to gainful employment, and 'may serve to promote an impoverished form of employability and reinforce the class-based divisions of labour that continue to characterise the English economy' (Simmons 2009, 137), it is perhaps important for further research to consider the progressive opportunities beyond re-engagement.

This study offers a brief, but important, comparative insight into the environments of school and WBL providers and highlights areas for further research, such as an exploration of the interplay between attitude and engagement in other contexts. As Kelly and Price $(2009,822)$ note, 'the hypothesis that vocational education benefits at-risk students should continue to be investigated.' We have seen that school disaffection can improve when learners engage in WBL (Hall and Raffo 2004), but its allure can also aid in negatively altering the student's perception of school if a link is not maintained. The connections between education and work are complex and multi-layered (Saunders 2006) and further research is needed to illustrate potential benefits of work-related activities for re-engagement. Thus, disaffection may appear problematic yet it rightly questions the nature of education.

\section{Consent}

Written informed consent was obtained from each student's guardian/parent/next of kin for the publication of this report and any accompanying images.

\section{Endnote}

${ }^{a}$ Aside from cultural and socioeconomic factors that can be influential, choice is often limited by vocational availability. However, the programme is not compulsory; therefore, it is argued that even though some limiting parameters exist, choice is still regarded as the individual pupil's decision.

\footnotetext{
Abbreviations

GCSE: General Certificate of Secondary Education (UK); LA: Local authority; NEET: Not in education, employment or training; WBLP: Work-based learning programme; WRL: Work-related learning.

Competing interests

The author declares that there are no competing interests.

Received: 9 June 2014 Accepted: 15 October 2014

Published online: 07 November 2014

References

Ahlgren L, Tett L (2010) Work-based learning, identity and organisational culture. Stud Contin Educ 32(1):17-27

Allan D (2014) Quantity for quality: a case study on the impact of an English work-based learning programme on disaffected pupils' qualification achievements. Educate 14(1):10-16

Avis J, Fisher R, Ollin R (2010) Professionalism. In: Avis R, Fisher R, Thompson R (eds) Teaching in lifelong learning: a guide to theory and practice. Open University Press, Maidenhead

Bentley T (1999) Learning beyond the classroom. Routledge, London

Billett S (2003) Vocational curriculum and pedagogy: an activity theory perspective. Eur Educ Res J 2(1):6-21
} 
Billett S (2006) Work, subjectivity and learning. In: Billett S, Fenwick T, Somerville M (eds) Work, subjectivity and learning: understanding learning through working life. Springer, Dordrecht

Bourdieu P, Passeron JC (2000) Reproduction in education, society and culture. Sage, London

Burr V (1995) An introduction to social constructionism. Routledge, London

Cuddy N, Leney T (2005) Vocational education and training in the United Kingdom, Cedefop. Panorama Series, 111 Office for Official Publications of the European Communities, Luxembourg

Davies J, Biesta G (2007) Coming to college or getting out of school? The experience of vocational learning of 14-to 16-year-olds in a further education college. Res Pap Educ 22(1):23-41

Dearing R (1996) Review of qualifications for 16-19 year olds. SCAA, London

DfE (2013) Full-time enrolment of 14-16 year olds in further education and sixth form colleges. DfE, London

DfE (2014) 2016 Key stage 4 performance tables: inclusion of 14 to 16 qualifications. DfE, London

DfES (2006) Work-related learning and the law. DfES, Nottingham

Felstead A, Fuller A, Unwin L, Ashton D, Butler P, Lee T (2005) Surveying the scene: learning metaphors, survey design and the workplace context. J Educ Work 18(4):359-383

Feng Y, Jament J (2009) Integrated but not included: exploring quiet disaffection in mainstream schools in China and India. Int J School Disaffection 6(1):12-18

Fuller C, Macfadyen T (2012) 'What With Your Grades?' Students' motivation for and experiences of vocational courses in further education. J Voc Educ Training 64(1):87-101

Fuller A, Unwin L, Felstead A, Jewson N, Kakavelakis K (2007) Creating and using knowledge: an analysis of the differentiated nature of workplace learning environments. Brit Educ Res J 33(5):743-759

Gall MD, Borg WR, Gall JP (1996) Educational research: an introduction, 6th edn. Longman, New York

Gov.UK (2014) Increasing opportunities for young people and helping them to achieve their potential., Available via https://www.gov.uk/government/policies/increasing-opportunities-for-young-people-and-helping-them-to-achievetheir-potential/supporting-pages/raising-the-participation-age. Accessed 17 Jan 14

Hall D, Raffo C (2004) Re-engaging 14-16-year-olds with their schooling through work-related learning. J Voc Educ Train 56(1):69-80

Harris R, Willis P, Simons M, Collins E (2001) The relative contributions of institutional and workplace learning environments: an analysis of apprenticeship training. J Voc Educ Train 53(2):263-278

Hodgson A, Spours K (2008) Education and training 14-19: curriculum, Qualifications and Organization. London, Sage

Hodgson A, Spours K (2010) Vocational qualifications and progression to higher education: the case of the 14-19 diplomas in the English system. J Educ Work 23(2):95-110

Humphrey N, Charlton JP, Newton I (2004) The developmental roots of disaffection? Educ Psych 24(5):579-594

Hyland C, Winch T (2007) Guide to vocational education and training. Continuum, London

James D, Simmons J (2007) Alternative assessment for learner engagement in a climate of performativity - lessons from an English case study. Assess Educ 14(3):353-371

Jamieson I (1993) TVEl and the work-related curriculum. Eval Res Educ 7(2):51-65

Jones T (2013) Through the lens of home-educated children: engagement in education. Educ Psych Pract 29(2):107-121

Kelly S, Price P (2009) Vocational education: a clean slate for disengaged students? Soc Sci Res 38(4):810-825

Klotz VK, Billett S, Winther E (2014) Promoting workforce excellence: formation and relevance of vocational identity for vocational educational training. Emp Res Voc Educ Training 6:6

Konkola R, Tuomi-Gröhn T, Lambert P, Ludvigsen S (2007) Promoting learning and transfer between school and workplace. J Educ Work 20(3):211-228

Kyndt E, Baert H (2013) Antecedents of employees' involvement in work-related learning: a systematic review. Rev Educ Res 83(2):273-313

Lovelace M, Brickman P (2013) Research methods: best practices for measuring students' attitudes toward learning science. Life Sci Educ 12(4):606-617

McKendrick J, Scott G, Sinclair S (2007) Dismissing disaffection: young people's attitudes towards education, employment and participation in a deprived community. J Youth Stud 10(2):139-160

Radnor H (2002) Researching your professional practice: doing interpretive research. Open University Press, Milton Keynes

Raelin JA (2010) Work-based learning: valuing practice as an educational event. New Dir Teach Learn 124:39-46

Raffo C (2003) Disaffected young people and the work-related curriculum at key stage 4: issues of social capital development and learning as a form of cultural practice. J Educ Work 16(1):69-86

Reay D (2001) Finding or losing yourself?: working-class relationships to education. J Educ Pol 16(4):333-334

Ritchie J, Ormston R (2014) The applications of qualitative methods to social research. In: Ritchie J, Lewis J, Nichols CM, Ormston R (eds) Qualitative Research Practice. Sage, London

Ross A (2009) Disengagement from education among 14-16 year olds. Research Report, DCSF RR178., Available via https://www.gov.uk/government/uploads/system/uploads/attachment_data/file/221992/DCSF-RR178.pdf. Accessed 12 Jan 14

Sandal A, Smith K, Wangensteen R (2014) Vocational students experiences with assessment in workplace learning. Voc Learn 7(2):241-261

Saunders M (2006) From 'organisms' to 'boundaries': the uneven development of theory narratives in education, learning and work connections. J Educ Work 19(1):1-27

Schaffer HR (2006) Social development. Blackwell, Oxford

Schmitt N, Oswald FL, Friede A, Imus A, Merritt S (2008) Perceived fit with an academic environment: attitudinal and behavioral outcomes. J Voc Behav 72(3):317-335

Simmons R (2009) Entry to employment: discourses of inclusion and employability in work-based learning for young people. J Educ Work 22(2):137-151

Slater SJ, Slater TF, Bailey JM (2011) Discipline-based science education research: a scientist's guide. Freeman, New York

Smith PJ (2003) Learning strategies used by apprentices in flexible delivery. J Voc Educ Train 55(3):369-383

Sodha S, Guglielmi S (2009) A stitch in time: tackling educational disengagement. Demos, London 
Swift J, Fisher R (2012) Choosing vocational education: some views from young people in West Yorkshire. Res Post-Comp Educ 17(2):207-221

Thompson R (2010) Teaching on the margins: tutors, discourse and pedagogy in work-based learning for young people. J Voc Educ Train 62(2):123-137

Thomson P, Russell L (2009) Data, data everywhere - but not all the numbers that count? mapping alternative provisions for students excluded from school. Int J Inclusive Educ 13(4):423-438

Virtanen A, Tynjälä P, Eteläpelto A (2014) Factors promoting vocational students' learning at work: study on student experiences. J Educ Work 27(1):43-70

Wolf A (2011) Review of vocational education - the Wolf report. DfE, London

Zemblyas M (2006) Work-based learning, power and subjectivity: creating space for a Foucauldian research ethic. Educ Work 19(3):291-303

doi:10.1186/s40461-014-0010-4

Cite this article as: Allan: Dealing with disaffection: the influence of work-based learning on 14-16-year-old students' attitudes to school. Empirical Research in Vocational Education and Training 2014 6:10.

Submit your manuscript to a SpringerOpen ${ }^{\circ}$ journal and benefit from:

- Convenient online submission

- Rigorous peer review

- Immediate publication on acceptance

- Open access: articles freely available online

- High visibility within the field

- Retaining the copyright to your article

Submit your next manuscript at $>$ springeropen.com 